\title{
SUBSÍDIOS TEÓRICOS PARA O DESIGN DA EXPERIÊNCIA EM ESPAÇOS PÚBLICOS: as noções de lugar e de experiência urbana a partir de um estudo de caso
}

\author{
André Guazzelli Afonso - UFMG
}

Resumo: O Design da Experiência tem dado grande ênfase às relações que se operam entre usuários e produtos. Entretanto, quando os projetos visam os espaços públicos urbanos, emergem questões de ordem espacial que devem ser adequadamente consideradas. Algumas dessas questões podem ser sintetizadas nos conceitos de lugar e de experiência urbana. Estes conceitos foram coligidos com os fundamentos do Design de Interação e deram origem à disciplina Design em Espaços Públicos, que é o estudo de caso do presente artigo. Aqui, são analisados três projetos de alunos daquela disciplina, os quais desenvolveram propostas de design orientado à experiência para uma praça central de Belo Horizonte. Os projetos são discutidos à luz das noções de lugar e de experiência urbana. Os resultados alcançados indicam que é possível implementar a problemática espacial no Design da Experiência de modo a gerar melhores soluções de projeto em contextos urbanos.

Palavras-chave: Design da Experiência, espaço público, lugar, experiência urbana.

Abstract: Experience Design has given great emphasis on relationships between users and products. However, when it comes to urban public spaces, there are some spatial issues that have to be considered. Some of these issues can be summarized in the concepts of place and urban experience. These concepts, along with the fundamentals of Interaction Design, gave rise to the discipline Design in Public Spaces, the case study of this article. Three projects from that discipline are analysed; the students developed proposals of experience-oriented design for a central square in Belo Horizonte. The projects are discussed on the basis of the notions of place and urban experience. The results indicate that it is possible to implement the spatial issue in Experience Design in order to generate better design solutions in urban contexts.

Keywords: Experience Design, public space, place, urban experience. 


\section{INTRODUÇÃO}

Este trabalho traz para o Design da Experiência alguns aspectos de natureza espacial diretamente associados à experiência humana. Apresenta reflexões particularmente importantes para o projeto de produtos e sistemas aplicados em espaços públicos. Seu principal objetivo é expandir a compreensão do Design da Experiência, através dos conceitos de lugar e de experiência urbana. Entende-se que essas noções sejam fundamentais para qualquer projeto de design em espaços públicos, e para discuti-las deve-se conjugar os fatores humanos e experienciais às preocupações de ordem espacial e tecnológica. Com isso, espera-se que os projetos de design no espaço público urbano, em suas variadas vertentes e manifestações, possam se beneficiar de uma visão mais rica e abrangente da experiência humana no espaço.

O método adotado é o estudo de caso, que consiste na disciplina Design em Espaços Públicos. Com base nos fundamentos do Design da Experiência, bem como nos conceitos de lugar e de experiência urbana, são analisados três projetos de sistemas interativos digitais que foram desenvolvidos por alunos daquela disciplina. A análise dos projetos permite apontar algumas dificuldades inerentes ao tema em foco, cuja natureza transdisciplinar e complexa levanta uma série de questões para debate. Mas, por outro lado, o exame dos resultados também revela o potencial existente nos conceitos de lugar e de experiência urbana para o estudo e a implantação de sistemas interativos nos espaços públicos.

O presente artigo está estruturado da seguinte maneira: a primeira parte contém alguns subsídios teóricos que fundamentam todo o debate - notadamente as noções de lugar e de experiência urbana. Em seguida, detalha-se a metodologia empregada no trabalho. Na terceira parte, há uma apresentação sumária dos três projetos desenvolvidos para o estudo de caso. Esses projetos são discutidos um a um, à luz dos conceitos abordados previamente. $O$ artigo termina tecendo considerações gerais acerca do alcance, do potencial e dos limites de se conjugar os fatores humanos, espaciais e tecnológicos no design de sistemas interativos urbanos.

\section{SUBSÍDIOS TEÓRICOS}

Uma vez que o Design da Experiência possui forte potencial de aplicação em sistemas e interfaces situados em contextos urbanos, é necessário considerar com cuidado as relações entre as pessoas e o meio ambiente físico das cidades. Dessa forma, o produto ou sistema concebido tende a responder melhor às demandas do local e aos anseios de seus usuários.

No entanto, trazer as preocupações de cunho espacial e sociocultural para a prática do design, particularmente do Design da Experiência, não é uma tarefa simples. Apesar do Design da Experiência ser um campo de estudo bastante abrangente, que inclui uma trama de aspectos humanos, espaciais e temporais (McCARTHY \& WRIGHT, 2004; SHEDROFF, 2008), parece haver uma carência de reflexão e de ferramentas teórico-metodológicas capazes de informar projetos de design aplicados em espaços públicos urbanos.

Para ajudar a preencher essa lacuna, o presente trabalho apresenta as noções de lugar e de experiência urbana. Posteriormente, tais noções serão confrontadas com um estudo de caso. Assim, espera-se contribuir para futuros projetos de Design da Experiência aplicados em espaços públicos. 


\subsection{A noção de lugar}

O estudo do conceito de lugar desponta com maior ênfase na década de 1970, por meio de um ramo da Geografia Cultural centrado na experiência vivida (CLAVAL, 2008). Para essa vertente disciplinar, interessa as percepções e sensibilidades individuais, além dos sentidos que as pessoas atribuem aos espaços: "A geografia torna-se uma disciplina das cores, dos sons, do movimento - uma disciplina da realidade concreta" (CLAVAL, 2008, p. 20). Em síntese, o espaço concreto, percebido e vivenciado pelos indivíduos torna-se lugar.

O lugar transcende o mero espaço físico das cidades. Segundo o antropólogo Marc Augé (2007), o lugar apresenta três características interdependentes: ele é identitário, relacional e histórico. Ou seja, ele porta uma identidade própria, fruto das dinâmicas sociais e culturais ali estabelecidas. O lugar também é, por natureza, relacional, isto é, constrói-se a partir das relações com outros lugares, estímulos, contextos. Além disso, a conjugação de identidades e relações próprias, ao conhecerem uma estabilidade mínima, o torna lugar histórico (AUGÉ, 2007).

O geógrafo Yi-Fu Tuan estuda o lugar sob a ótica da experiência. Ele descreve o lugar como o espaço humanizado, familiar, dotado de significado e valor. O significado nasce das relações humanas que o lugar acolhe, e para fortalecê-las o fator tempo é essencial, ou seja, aquelas relações precisam de certa duração, permanência e estabilidade (TUAN, 1983). São as experiências cotidianas que nos permitem sentir o lugar, e para isso dependemos diretamente do corpo, do nosso aparelho sensóriomotor, das percepções e emoções subjetivas. Logo, a compreensão do conceito de lugar retoma vários aspectos que norteiam o Design da Experiência.

Tanto a ideia de lugar quanto a de experiência comportam duas noções-chave: a subjetividade e o significado. Por um lado, o lugar nasce de relações simbólicas e significativas entre indivíduos e espaços, no seio de um quadro histórico e cultural específico. Em contrapartida, a experiência, que deu origem a um novo campo do Design a partir da década de 1990 (FORLIZZI, 2010), consiste nas relações entre usuários e produtos, cabendo ao designer desvendar os meios de torná-las mais satisfatórias, duradouras e significativas.

A experiência é matizada pela conexão entre valores, necessidades e ações, sendo inseparável do domínio do afeto e das emoções (HASSENZAHL; DIEFENBACH; GORITZ, 2010). Portanto, as questões suscitadas pelo Design da Experiência transcendem os requisitos de usabilidade, ergonomia e eficiência do produto ou serviço oferecido. De um ponto de vista mercadológico, a vantagem competitiva não mais se limita a entregar produtos convenientes, mas soluções que deflagrem experiências significativas; um design que faça as pessoas se importarem (NORTON, 2010).

De modo análogo, os lugares não se resumem aos locais geográficos onde os cidadãos circulam e têm suas necessidades pragmáticas atendidas. As cidades contemporâneas estão cheias de espaços funcionais e sem vida, porque desprovidos de significados, afetos e memórias. O lugar, ao contrário, é um "centro calmo de valores estabelecidos" (TUAN, 1983); ou "focos onde se experimentam os acontecimentos significativos da existência"1 (NORBERG-SCHULZ, 1999, p. 226). Esses

\footnotetext{
${ }^{1}$ No original: "Los lugares son metas o focos donde se experimentan los acontecimientos significativos de la existencia."
} 
"acontecimentos significativos" se expressam, muitas vezes, nas interações triviais e rotineiras que ocorrem em determinados lugares da cidade, as quais reforçam os vínculos entre as pessoas e aquele contexto urbano. 0 mesmo tipo de fenômeno se observa no Design da Experiência: os vínculos entre usuários e produtos consolidam-se no dia a dia, se estendem no tempo, até que o produto ajuda a identificar o próprio sujeito.

A importância do lugar para a experiência com produtos e marcas é reconhecida há muito tempo, conforme aponta David Norton (2010). Prova disso é a presença marcante de lojas e painéis publicitários em locais estratégicos das cidades, a exemplo da Times Square, em Nova York, e da Piccadilly Circus, em Londres, para citar dois casos emblemáticos. Os atributos significativos de lugares como esses são construídos ao longo dos anos e resultam numa grande atratividade para um vasto público; são lugares que têm sua imagem propalada ao redor do globo. A estratégia das marcas consiste em tomar de empréstimo os fortes vínculos humano-espaciais que se processam nos lugares para forjar novos vínculos entre a marca e os usuários do lugar.

Portanto, pensar o Design da Experiência em espaços públicos implica considerar a natureza e as dinâmicas de cada lugar. As relações específicas e profundas que dão sentido à ideia de lugar podem ser melhor captadas por meio da noção de experiência urbana.

\subsection{A experiência urbana}

Confrontando-se as noções de espaço e lugar, é possível estabelecer um conceito de experiência urbana que ajude a informar projetos de Design da Experiência em espaços públicos.

Marc Augé (2007) assinala que o espaço é uma noção eminentemente abstrata, pouco simbólica e plurissemântica: ora designa a distância entre dois pontos, ora um local específico na superfície terrestre, ora refere-se a fenômenos diversos - o "espaço publicitário", o "espaço virtual", o "espaço aéreo", e tantos outros. De modo geral, a ideia de espaço está mais alinhada às ciências exatas e à tradição racionalista, com seus esforços de objetivação e abstração.

No âmbito das Ciências Humanas e Sociais, e particularmente da Arquitetura e do Design, o conceito de espaço traz em seu bojo quesitos de ordem técnica e utilitária. Tais quesitos são de suma importância, pois sem eles qualquer interação entre usuários e espaços, ou entre usuários e produtos, tornaria-se inviável. Assim, o espaço eletrônico de uma interface web deve ser programado para possibilitar uma navegação eficiente e fluida; o espaço urbano precisa ser planejado para acolher as funções das cidades, como circulação, produção, consumo e moradia.

Em suma, projetos no meio urbano atentos ao espaço podem entregar soluções eficientes e usáveis, capazes de atender aos requisitos clássicos do Design de Interação. Todavia, o Design da Experiência coloca em pauta uma série de outros requisitos e demandas, conforme discutido na seção anterior. Assim, Malcolm McCullough (2004) sustenta que o Design da Experiência enfatiza a satisfação, que não vem apenas ao se preencher expectativas, mas também ao se transformá-las. Nesse sentido, o design deve proporcionar experiências significativas, refletindo nossas aspirações, valorizando memórias coletivas e fornecendo um repositório para diversos valores (McCULLOUGH, 2004). 
Para contemplar os requisitos do Design da Experiência em contextos urbanos, a noção de lugar é mais produtiva que a de espaço. Os espaços respondem aos usos; os lugares suscitam experiências. As pessoas utilizam os espaços que the servem e experienciam os lugares que lhe são marcantes ${ }^{2}$. Quando os aspectos experienciais do design são considerados no meio ambiente urbano, pode-se falar em experiência urbana. E, também com base nos conceitos norteadores da experiência, pode-se definir a experiência urbana como toda prática espacial subjetiva e significativa.

Logo, o design orientado à experiência urbana deve reconhecer e valorizar as características que dão e vida e significado a um lugar. Quais são as práticas sociais marcantes do lugar? Que elementos espaciais estimulam ou inibem aquelas práticas? Como um projeto de design pode realçar os aspectos positivos e ampliar os vínculos da população com o contexto urbano? Essas são algumas questões que aparecem ao se pensar o Design da Experiência em espaços públicos.

Segundo Olivier Mongin (2009), a reconquista da experiência urbana implica a reconquista dos lugares. Em se tratando de projetos instalados no espaço público, tais como sistemas de informação e de sinalização, mídias digitais interativas e as aplicações tecnológicas emergentes da Computação Ubíqua, é imprescindível que os designers se atentem para a realidade do lugar e como potencializar as experiências urbanas das pessoas que o vivenciam. Dessa forma, o Design da Experiência pode contribuir para tornar as cidades mais humanas, mais vinculadas aos seus habitantes e, consequentemente, mais vivas e seguras.

As noções de lugar e de experiência urbana serão, agora, aplicadas na análise de três projetos de design em espaços públicos. Com isso, pretende-se esclarecer a validade, o alcance e os limites dos subsídios teóricos apresentados.

\section{METODOLOGIA}

O método utilizado para avaliar os conceitos desta pesquisa é o estudo de caso. Este parece ser o procedimento mais adequado porque os fenômenos aqui examinados são indivorciáveis de seu contexto. O estudo de caso compreende a disciplina Design em espaços públicos, e o objeto de análise consiste de três projetos desenvolvidos individualmente por estudantes daquela disciplina.

O curso de Design em espaços públicos estruturou-se em três etapas: na primeira parte, foram discutidos com os alunos uma série de conceitos relacionados ao design em espaços públicos, desde os fundamentos do Design de Interação até as considerações teóricas do lugar e da experiência urbana. De posse desses conhecimentos, os estudantes deveriam desenvolver projetos orientados à experiência, explorando, tanto quanto possível, os recursos de Tecnologia da Informação (T.I.). O local designado para o projeto foi a praça Raul Soares e seu entorno imediato, uma área situada na região central de Belo Horizonte. Na etapa final do curso, cada aluno formulou um relato crítico confrontando os conceitos estudados com o projeto resultante.

\footnotetext{
${ }^{2}$ A forma verbal "experienciar" é tomada emprestada de FORLIZZI \& BATTARBEE (2004), designando o fluxo de ação contínua e consciente, incluindo os objetivos que traçamos em relação às pessoas, produtos e ambientes que nos cercam em dado momento.
} 


\subsection{O lugar e a experiência urbana na Praça Raul Soares}

A praça Raul Soares configura o objeto empírico desta pesquisa. A fim de fundamentar a análise dos projetos, que serão apresentados no próximo tópico, cabe apresentar os aspectos principais que qualificam a praça Raul Soares como um lugar, bem como o tipo de experiência urbana que a praça pode deflagrar em seus usuários.

Inaugurada em 1936, a Praça Raul Soares ocupa uma posição de destaque na área central de Belo Horizonte. Trata-se de um dos principais pontos de ligação da capital mineira: por suas adjacências circulam diariamente milhares de veículos e pedestres. A praça, com seu desenho art déco, além do entorno edificado - que apresenta um importante conjunto arquitetônico e urbanístico - constituem um verdadeiro marco urbano, de grande valor cultural, social e histórico.

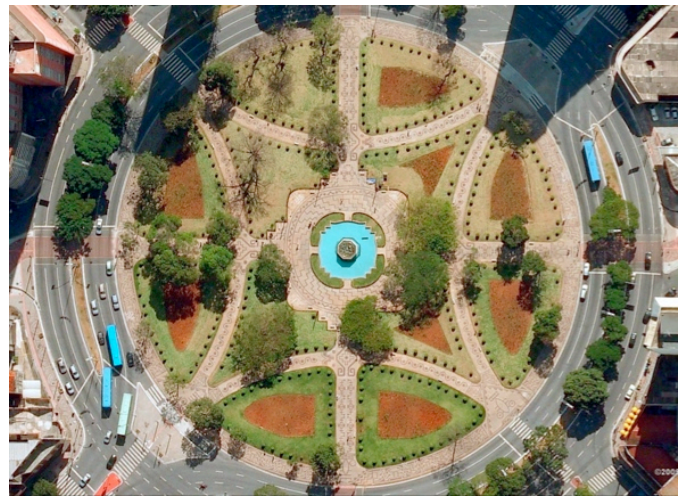

Figura 1 - Vista aérea da Praça Raul Soares. Fonte: Google Maps.

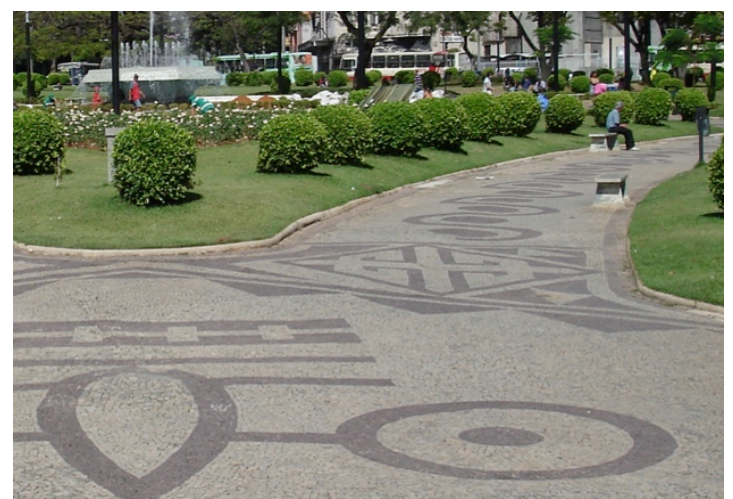

Figura 2 - Vista parcial da Praça Raul Soares. Fonte: Fotografia do autor.

O espaço físico da praça Raul Soares não funciona apenas como local de travessia. Seus ambientes oferecem uma oportunidade de descanso, lazer e contemplação para uma importante parcela das pessoas que residem ou trabalham na vizinhança. Cercados por prédios e por vias de tráfego intenso, os amplos jardins da praça representam uma quebra no ritmo de vida das avenidas centrais. Seus caminhos bucólicos e seus bancos convidam ao andar vagaroso, à parada, parecem acenar com a suspensão momentânea do tempo, das pressões e opressões urbanas. $E$, atentas a essa possibilidade, muitas pessoas usufruem daquele espaço de formas especiais, significativas: elas fazem daquela praça um lugar.

Uma série de observações e mapeamentos da praça revelou que ela acolhe usos e experiências diversificados nos vários períodos do dia e nos diferentes dias da semana. Durante a manhã, é comum observar crianças acompanhadas dos pais circulando pela praça, principalmente na área central, em torno da fonte. Nos dias mais quentes, e sobretudo à tarde, a praça Raul Soares é mais utilizada como local de travessia. Em compensação, à noite o caráter de lugar torna-se evidente, pois todas as atividades verificadas ao longo do dia são potencializadas. Assim, o anel externo da praça serve de pista de caminhada para a população do entorno. Enquanto isso, outras pessoas ocupam os bancos perto da fonte, ou permanecem em pé; umas conversam, outras namoram, outras tantas passeiam com os filhos, às vezes com os cães, numa rotina aparentemente trivial, mas que forja a noção de lugar, e que torna este lugar significativo para elas. 
Como todo produto de design, o espaço arquitetônico e urbano deve, em última análise, propiciar experiências ricas e valiosas. Nesse processo atuam diversos fatores de ordem corporal e espiritual: os sentidos inatos, as percepções e emoções individuais, as memórias e expectativas de cada um. A experiência espacial, e o Design da Experiência como um todo, referem-se mais a verbos do que a substantivos (PALLASMAA, 2005): o usuário sente o objeto, percorre o espaço, interage com a mídia, ou seja, ele não se limita a apreender os atributos visuais de uma fachada ou produto. Nesse sentido, as práticas espaciais corriqueiras e significativas da praça Raul Soares devem ser interpretadas como experiências urbanas próprias daquele lugar.

No Design da Experiência, também participam aspectos de natureza social e cultural, os quais ajudam a definir a identidade dos indivíduos. Aqui, o espaço público assume um papel central, na medida em que empresta um sentido de coletividade às experiências, gerando a "co-experiência", isto é, a experiência subjetiva em contextos sociais (FORLIZZI; BATTARBEE, 2004) - experiências que muitas vezes são criadas e compartilhadas nas ruas da cidade. Então, a co-experiência na praça Raul Soares nasce da rede de interações entre os seus usuários. Os vínculos afetivos de cada pessoa com a praça tendem a criar vínculos em outras pessoas, e com o tempo o lugar da praça torna-se mais significativo, mais arraigado à vida cotidiana daquela comunidade.

\section{ESTUDO DE CASO}

A seguir, os três projetos da disciplina Design em espaços públicos serão apresentados e discutidos à luz dos conceitos de lugar e de experiência urbana. A análise visa iluminar possíveis aproximações do Design de Experiência em espaços públicos, e como os sistemas e interfaces podem ser empregados para fortalecer os lugares e contribuir para melhores experiências urbanas.

\subsection{Projeto 1}

O primeiro projeto a ser discutido estabelece uma série de interferências na praça Raul Soares e em suas áreas contíguas (FIGURAS 3 e 4). O estudante propõe:

- a instalação de relógios digitais em alguns pontos da praça, para que os frequentadores possam controlar o tempo de suas atividades físicas, especialmente as caminhadas e corridas em torno da praça;

- a instalação de sensores eletrônicos ao longo de seu perímetro, os quais informariam, mediante o uso de pulseiras digitais ou celulares, a evolução de cada percurso;

- a instalação de painéis eletrônicos sobre duas fachadas do entorno; tais painéis exibiriam conteúdo variado, como mapas, previsão do tempo, temperatura e outras informações de interesse geral;

- a demarcação dos pisos da região com cores distintas, com o objetivo de orientar o público que circula pela área; a cada avenida que intercepta a praça seria atribuída uma cor, presente nos canteiros centrais das vias e no anel externo da praça (ANTERO, 2012). 


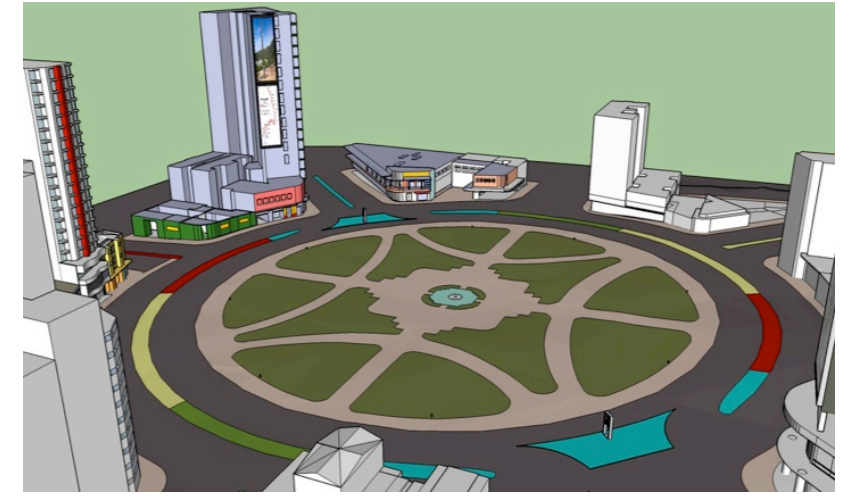

Figura 3 - Perspectiva geral do Projeto 1.

Fonte: ANTERO, 2012.

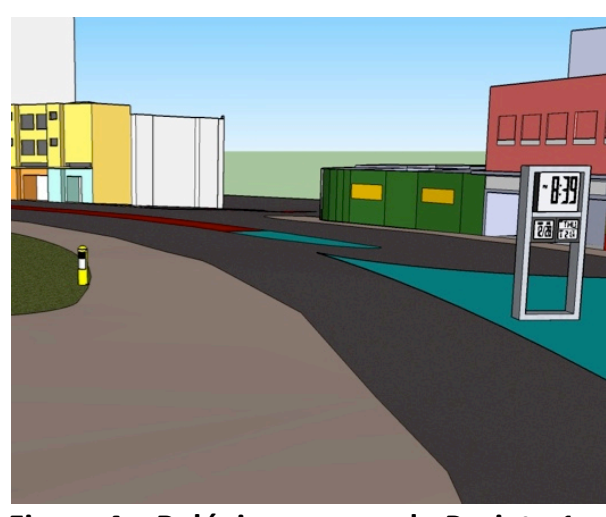

Figura 4 - Relógio e sensor do Projeto 1. Fonte: ANTERO, 2012.

Os relógios e sensores eletrônicos do projeto 1 procuram dar suporte às atividades físicas dos frequentadores da praça Raul Soares. Sob a ótica do Design da Experiência, tais medidas oferecem vários benefícios: (a) estimulam o corpo dos usuários a se movimentar, a percorrer o espaço da praça; (b) acenam com a surpresa e provocam a curiosidade das pessoas; (c) convidam ao engajamento com o espaço público, o qual, uma vez incorporado à rotina dos frequentadores, tende a ampliar a permanência na praça e os laços sociais ali existentes; (d) ao estimularem o uso contínuo da praça, criam vínculos emocionais e simbólicos com o lugar, propiciando experiências urbanas em mais pessoas.

Com relação aos painéis eletrônicos nas fachadas do entorno, e embora esses dispositivos possam oferecer informações de utilidade pública, eles não parecem contribuir para o fortalecimento da praça enquanto lugar. Da forma como está proposto, o conteúdo veiculado não reconhece nem valoriza qualquer atributo simbólico, cultural ou histórico daquele contexto urbano. Ao contrário, os painéis insinuam-se como televisões a céu aberto, emitindo informações descoladas do cotidiano socioespacial da praça. Painéis informativos desse tipo poderiam ser instalados em qualquer espaço público, seja na sala de embarque de um aeroporto ou numa esquina de outra cidade.

A demarcação cromática da praça e das vias adjacentes, apesar de ser uma proposta bastante simples e sem o uso da T.I., pode gerar ganhos para o lugar e a experiência urbana. As cores não só auxiliam a orientação dos pedestres e veículos, como também identificam e particularizam aquele contexto urbano. A orientação é fundamental para que as pessoas se sintam seguras no lugar, e a praça Raul Soares, interceptada por quatro avenidas, às vezes se torna confusa para a população.

\subsection{Projeto 2}

O segundo projeto lança mão de três soluções independentes (FIGURAS 5 e 6):

- a construção das chamadas "coberturas culturais", que consistem de quatro corredores metálicos vazados cruzando a praça. No interior dessas coberturas a estudante propõe a instalação de telas interativas com a programação cultural da região;

- a instalação de "lixeiras interativas", que atuariam em conjunto com totens digitais. Através de sensores, a cada uso das lixeiras o totem emitiria uma mensagem audiovisual de agradecimento pelo gesto de civilidade; 
- as "calçadas de LEDs", obtidas pela aplicação de LEDs vermelhos sobre todos os grafismos em pedra portuguesa que adornam os caminhos da praça; estes seriam iluminados pela pisada das pessoas e apagados quando cessada a pressão (JOTA, 2012).

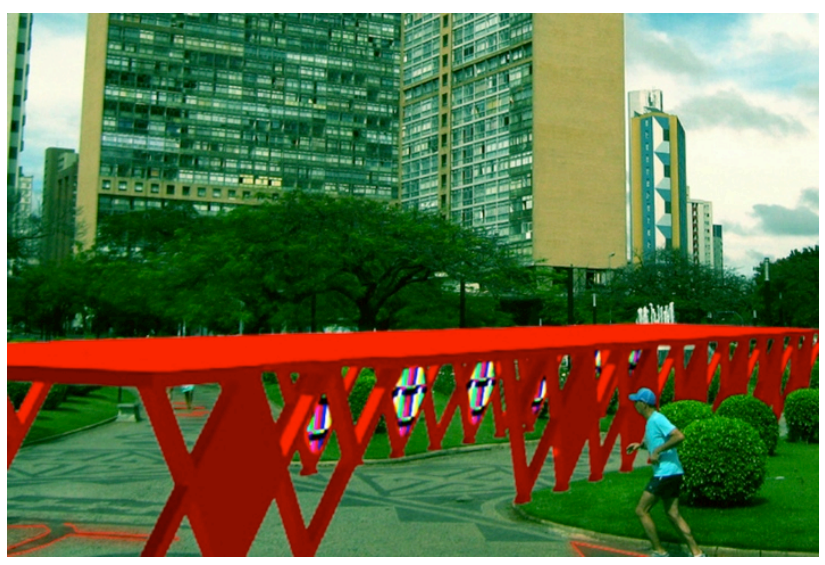

Figura 5 - Vista do "corredor cultural" e da "calçada LED." Fonte: JOTA, 2012.

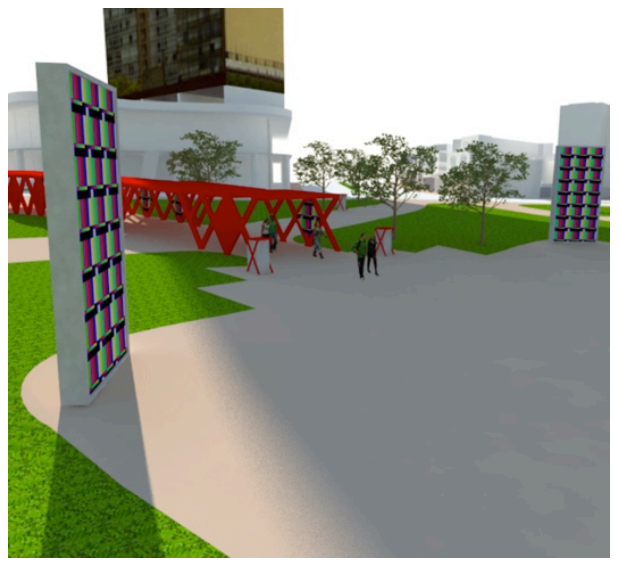

Figura 6 - Vista dos totens e lixeiras. Fonte: JOTA, 2012.

As "coberturas culturais" do projeto 2 possuem alguns aspectos positivos para o lugar e a experiência urbana. Suas estruturas vazadas sugerem privacidade, conforto e acolhimento no ambiente da praça. Elas filtram a radiação solar e orientam os pedestres, o que beneficia inclusive a população que utiliza aquele espaço para travessia. As telas com programação cultural são um estímulo a mais para a permanência no lugar, apesar de não responderem a uma demanda empírica da praça.

As "lixeiras interativas" e os totens constituem um elemento de surpresa e estranhamento, fatores caros ao Design de Experiência. Eles apresentam um caráter lúdico que rompe com a expectativa dos usuários da praça. São artefatos que despertam o interesse, aliando a utilidade da limpeza urbana à cordialidade da mensagem de agradecimento. Entretanto, o design das lixeiras e dos totens não se adere a qualquer elemento espacial, social ou cultural da praça, ou seja, não reforçam os atributos simbólicos do lugar. A exemplo dos painéis digitais do Projeto 1 , são artefatos perfeitamente replicáveis em qualquer outro contexto urbano.

As chamadas "calçadas de LEDs" são a proposta mais atenta às qualidades e à experiência do lugar. Todos os caminhos da praça Raul Soares são adornados com grafismos de inspiração marajoara, desenhados com pedras portuguesas e originais de sua inauguração. Ao iluminar com LED os grafismos, põe-se em evidência esse rico patrimônio urbano, que, a despeito de seu valor histórico e cultural, às vezes passa despercebido para as pessoas que atravessam a praça.

Os caminhos iluminados parecem mesmo convidar os pedestres a uma caminhada exploratória, e à medida que os espaços são percorridos as luzes desvelam formas surpreendentes, composições gráficas até então adormecidas. Assim, a proposta tem forte potencial de deflagrar experiências urbanas, conjugando o movimento do corpo ao encantamento, à surpresa perceptiva, à emoção que resulta em novas relações com o lugar, a partir de qualidades intrínsecas ao próprio lugar. 


\subsection{Projeto 3}

O Projeto 3 é o que apresenta as maiores alterações na praça Raul Soares. A estudante propõe as seguintes medidas (FIGURAS 7 e 8 ):

- a substituição de quatro canteiros da praça por espelhos d'água inclinados. Nestas superfícies seria projetado conteúdo variado, como informes sobre o trânsito, o clima, eventos culturais e propagandas. Na área sob os espelhos d'água haveria lojas, em cujas fachadas a estudante propõe a instalação de painéis de LED; o conteúdo veiculado pelos painéis não foi especificado;

- A projeção de luzes coloridas sobre os quatro canteiros restantes da praça. As cores representariam o estado de ocupação dos bancos da praça, variando de cores frias, para mais bancos ociosos, até cores quentes, indicando menos bancos disponíveis (CAMPOS, 2012).

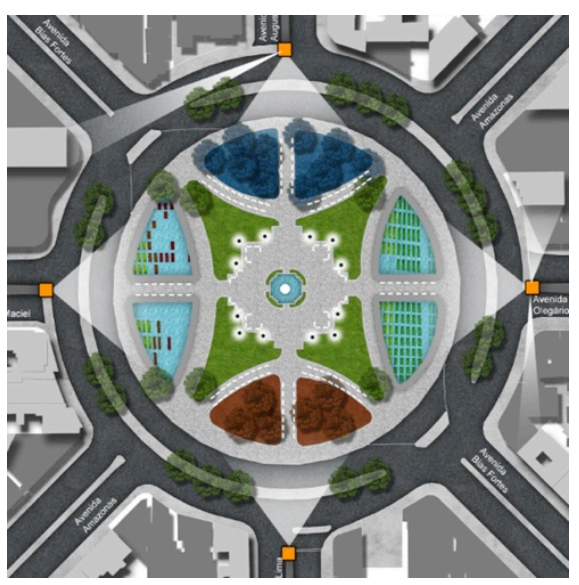

Figura 7 - Vista geral do Projeto 3

Fonte: CAMPOS, 2012.

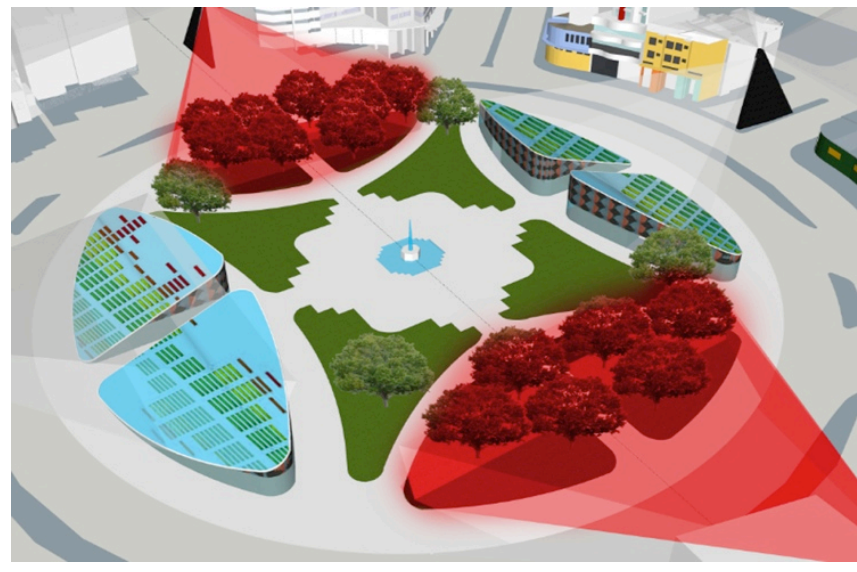

Figura 8 - Perspectiva das projeções de luzes do Projeto 3. Fonte: CAMPOS, 2012.

A primeira proposta do Projeto 3 abrange interferências físicas radicais na praça, com a construção de lojas na área correspondente a quatro canteiros. Trata-se de uma medida muito mais vinculada à Arquitetura do que ao Design da Experiência, desviando-se, portanto, do escopo deste debate. ${ }^{3} \mathrm{Em}$ todo caso, considerando-se apenas os espelhos d'água sobre os quais seriam projetadas informações de utilidade pública, a proposta recai no mesmo problema identificado nos projetos anteriores, pois não há qualquer relação das mensagens visuais com a realidade social, cultural e espacial da praça Raul Soares. Além disso, se os espelhos d'água fossem instalados sobre as lojas, eles dificilmente seriam visíveis às pessoas que circulam pela área.

A segunda proposta transforma os canteiros restantes da praça em sistemas de sinalização, por meio da projeção de luzes coloridas. O maior mérito do sistema é o de atender a um dos principais usos daquele espaço: em determinadas horas do dia, os 48 bancos existentes na praça são bastante disputados. Portanto, a solução focaliza uma demanda concreta e ordinária do espaço, sinalizando para as pessoas que

\footnotetext{
${ }^{3}$ Uma abordagem holística do Design da Experiência não prescinde das questões arquitetônicas ou espaciais, conforme discutido no início deste artigo. Porém, soluções de natureza construtiva fogem ao escopo desta análise, cujo foco são os componentes e sistemas tecnológicos aplicados no espaço público.
} 
circulam pelas ruas próximas o estado de ocupação dos bancos em cada momento. Em contrapartida, tal recurso parece ser de difícil implementação durante o dia, com a luz do sol incidindo diretamente sobre os canteiros.

As projeções de luzes nos canteiros parecem aproximar as preocupações utilitárias do Design de Interação ao domínio emocional e simbólico do Design da Experiência. Um sistema de sinalização assim concebido seria respaldado por uma realidade palpável de uso de um espaço público - neste caso, o hábito local de assentar-se numa praça para diversos fins. Este hábito configura um elemento importante para a noção de lugar, porque diz respeito, simultaneamente, a um espaço, a um tempo e a uma cultura que caracterizam uma comunidade específica. Sem perder sua função utilitária, a sinalização com luzes coloridas desponta como elemento atrativo de curiosidade e surpresa no meio urbano; endereçam o nível afetivo e emocional das pessoas, ajudando a promover laços significativos entre elas e a praça, ou seja, promovem a experiência urbana.

\section{CONSIDERAÇÕES FINAIS}

A hipótese discutida neste artigo sustenta que todo projeto de design orientado à experiência que interfere no espaço público urbano deve se ater a duas noções-chave: o lugar e a experiência urbana. Significa dizer que, à trama de relações significativas entre usuários e produtos, o design deve adicionar outra camada de relações, igualmente relevantes, que vinculam o ser humano ao espaço físico vivenciado.

O estudo de caso permite tecer algumas considerações acerca do potencial e das dificuldades de se contemplar o lugar e a experiência urbana em propostas de design em espaços públicos. Os três projetos analisados lançam mão de telas ou projeções digitais para divulgar conteúdo variado de "utilidade pública". No entanto, o tipo de conteúdo proposto não se apega à realidade urbana da praça Raul Soares, aí incluídos seus aspectos espaciais, sociais, simbólicos e culturais. Portanto, mensagens visuais de utilidade pública não são elementos suficientes para fortalecer o sentido de lugar.

Por outro lado, os projetos também indicam diretrizes potencialmente favoráveis às noções de lugar e de experiência urbana. O Projeto 1 especifica um sistema de relógios e sensores para estimular as atividades físicas na praça, reforçando os laços sociais e os vínculos com o lugar. As "calçadas de LEDs" do Projeto 2 valorizam um elemento significativo da praça Raul Soares - os padrões gráficos do piso - e ao mesmo tempo estimulam a permanência e a circulação das pessoas. Já o Projeto 3, com suas projeções de luzes coloridas sobre os canteiros da praça, consegue atrelar o lado utilitário da sinalização ao domínio emocional dos frequentadores, emergindo como um elemento de surpresa no espaço público, de grande valor para experiência urbana.

Incluir no Design da Experiência os fatores espaciais que dão sentido ao lugar e à experiência urbana é, sem dúvida, um desafio a ser perseguido. Uma perspectiva teórico-metodológica atenta às relações entre experiência e lugar suscita muitos desdobramentos e leituras possíveis. Enquanto processo de design, o resultado será mais rico e proveitoso à medida que novas práticas e conhecimentos forem trazidos para a discussão. 


\section{REFERÊNCIAS}

ANTERO, Antonio Zeferino. Praça Raul Soares. Trabalho apresentado como requisito parcial para a aprovação na disciplina Design em Espaços Públicos, Curso de Arquitetura e Urbanismo, UFMG, 2012.

AUGÉ, Marc. Não-lugares: introdução a uma antropologia da supermodernidade. Campinas: Papirus, 2007.

CAMPOS, Miriã Tamiris. Intervenção multimidiática na Praça Raul Soares. Trabalho apresentado como requisito parcial para a aprovação na disciplina Design em Espaços Públicos, Curso de Arquitetura e Urbanismo, UFMG, 2012.

CLAVAL, Paul. Uma, ou algumas, abordagem(ns) cultural(is) na geografia humana? In: - Espaços culturais: vivências, imaginações e representações. Salvador: EDUFBA, 2008. P. 13-29.

FORLIZZI, Jodi; BATTARBEE, Kajta. Understanding Experience in Interactive Systems. In: Proceedings of the 2004 Conference on Designing Interactive Systems (DIS 04): Processes, Practices, Methods, and Techniques. New York: ACM, 2004. P. 261-268.

FORLIZZI, Jodi. All look same? A comparison of Experience Design and Service Design. In: Interactions. New York: ACM, September/October 2010. P. 60-62.

HASSENZAHL, Marc; DIEFENBACH, Sarah; GORITZ, Anja. Needs, affect, and interactive products: facets of user experience. In: Interacting with Computers, N. 22, Vol. 5, 2010. P. 353-362.

JOTA, Bárbara Scorsulini. Praça Raul Soares: Superfícies Midiáticas Urbanas. Trabalho apresentado como requisito parcial para a aprovação na disciplina Design em Espaços Públicos, Curso de Arquitetura e Urbanismo, UFMG, 2012.

McCARTHY, John; WRIGHT, Peter. Technology as Experience. In: Interactions. New York: ACM, September/October 2004. P. 42-43.

McCULLOUGH, Malcolm. Digital ground: architecture, pervasive computing, and environmental knowing. Cambridge, Mass.: MIT Press, 2004.

MONGIN, Olivier. A condição urbana. São Paulo: Estação Liberdade, 2009.

NORBERG-SCHULZ, Christian. Arquitectura occidental. Barcelona: Gustavo Gili, 1999.

NORTON, David. Will meaningful brand experiences disrupt your market? In: LOCKWOOD, Thomas (Org.). Design thinking: integrating innovation, customer experience and brand value. New York: Allworth Press, 2010.

PALLASMAA, Juhani. The eyes of the skin: architecture and the senses. Chichester, Hoboken: Wiley-Academy, John Wiley \& Sons, 2005.

SHEDROFF, Nathan. Design: A Better Path to Innovation. In: Interactions. New York: ACM, November/December 2008. P. 35-41.

TUAN, Yi-Fu. Espaço e lugar: a perspectiva da experiência. São Paulo: Difel, 1983. 